\title{
Masculinity and femininity from many perspectives
}

\author{
MELISSA HINES \\ School of Medicine, University of California, Los Angeles, California
}

\section{Masculinity/Femininity: Basic Perspectives \\ Edited by June Machover Reinisch, Leonard A. Rosen- blum, and Stephanie A. Sanders. 1987, Oxford Univer- sity Press. 364 pp. \$29.95.}

Masculinity/Femininity: Basic Perspectives is a volume of chapters based on a Kinsey Institute Symposium that brought together eminent researchers studying masculinity and femininity from a wide range of perspectives. The book provides an accessible and comprehensive introduction to the field for the unfamiliar and an informative update for the familiar. Two great strengths of the book are the breadth of the perspectives represented and the stature of the contributors, many of whom have played pivotal roles in establishing the research areas they describe.

The general organization of the book is to pair chapters, the first presenting a research area and the second commenting on the presentation. The first two chapters are from superstars in the universe of gender research. One, John Money, originated the terms gender role and gender identity in 1955, and since then has greatly advanced our understanding of the development of masculinity and femininity through his pioneering studies of gender-related characteristics in children born with ambiguous genitalia. The second, Frank Beach, trained many of the scientists currently studying masculinity and femininity and is widely regarded as the founder of the field of behavioral endocrinology. Other contributors are prominent neuroscientists (Roger Gorski and Bruce McEwen), evolutionary biologists (David Crews and Milos Novotny), primatologists (Ronald Nadler, Leonard Rosenblum, David Goldfoot, Deborah Neff, and Robert Goy), behavioral geneticists (Steven Vandenbergh and James Wilson), a behavioral endocrinologist (Anke Ehrhardt), developmental psychologists (Michael Lewis and Eleanor Maccoby), social psychologists (Jacquelynne Eccles, Kay Deaux, and Sandra Bem), and cultural anthropologists (Anya Royce and Lionel Tiger).

The paired format (presentation and commentary) works well. Typically, both authors are active in the same field of research, and the commentary supplements the information provided in the first presentation or points

Melissa Hines' mailing address is Department of Anatomy, UCLA School of Medicine, CHS, University of California, Los Angeles, CA 90024-1763. out areas of controversy or potential misunderstanding. Thus, the reader gets an overview of what each field has contributed to our understanding of masculinity and femininity, as well as two expert opinions on the important issues currently facing the field. One set of paired articles does not fit this format, however, and I found this pair to be the most illuminating.

Anke Ehrhardt, well known for studies investigating the impact of sex hormones on masculinity and femininity, comments on a chapter by Jacquelynne Eccles, a social psychologist. Although one of the strengths of this volume is its inclusion of both sociocultural and biological approaches to masculinity/femininity, these approaches rarely meet. The pairing of Eccles and Ehrhardt provides a thought-provoking exception. Eccles' chapter presents an expectancy value theory of sex differences in achievement patterns. The main point of the theory is that women are less likely to be found in what are generally considered high-achievement occupations (e.g., lawyer, engineer, physician, business executive), because they do not expect to do well at tasks related to these careers and they do not value success at these careers as highly as do men. These expectations and values are, in turn, thought to result from various factors, the most influential of which is theorized to be gender roles and their socialization. Ehrhardt points out that Eccles' theory is useful as it stands, but might be improved by incorporating biological variables. She cites several studies relating levels of sex hormones during the prenatal period to gender role behavior in childhood and one study that found women in professional, managerial, and technical occupations to have higher levels of male hormones than did women who were clerical workers and housewives. Ehrhardt also points out that behavior can influence hormone levels, so that high levels of male hormones could be a consequence as well as a cause of an occupational choice. Her point is not that biology is more important than socialization, but rather that both must be considered, not only as separate influences, but as interacting factors, if we are to understand masculinity and femininity.

The problem of incorporating biological and sociocultural factors into a single theory of masculinity/femininity may be the most important issue facing the field. The chapters in this book describe dramatic progress that has been made by researchers investigating one or the other type of influence. In the biological realm, our understand- 
ing of the roles of genetic and hormonal factors in the development of neurobehavioral sex differences has been expanded and extended to include human beings as well as laboratory animals. In addition, structural and biochemical sex differences have been identified in the nervous system that are allowing direct observation of the processes involved in becoming a functional male or female. In the sociocultural realm, ambiguous terms like masculine, feminine, and sex difference have been rigorously defined, methodologies for studying sex-related behavior have been refined, and the impact of the social environment on sex-linked behavior has been carefully documented in human beings as well as nonhuman primates. Almost all the authors point out the need to consider both sociocultural and biological factors in studying masculinity and femininity. Although no one directly addresses the question of how to do so, the information in this volume could provide the basis for an answer. To my mind, an important clue lies in a point made by several authors: Biology and the sociocultural environment are ultimately not separable, in that any influence on behavior, be it innate or learned, must be coded and manifested via the nervous system. With this in mind, it may be that structural and biochemical sex differences in the nervous system provide a "final common pathway," by which both biological and sociocultural influences on masculinity and femininity are integrated and expressed.

In addition to providing a general review of Masculinity/Femininity, I have been asked to evaluate its usefulness as a textbook. I teach a course on the biopsychology of masculinity and femininity, and, in the absence of the perfect text, have compiled a book of readings. The course raises many issues that are not addressed in Masculinity/Femininity, such as the implications of biological influences on behavioral sex differences for social roles of men and women or for laws regarding homosexuality. Other issues, such as the difficulty in defining sex differences, the fallacy of considering biology and environment as separable and opposing forces, and the political pressures that influence research on sex differences are mentioned in several chapters, but not addressed as systematically as I would like. I also find that many undergraduates need some review of neuroanatomy, endocrinology, and the philosophy of science to grapple effectively with the issues raised by the course. Hence, I favor my present system, since it allows me to select exactly which readings are included and to change them from year to year. However, the first time I taught the course,
I used a primary text (Sexual Differentiation of the Brain by Goy \& McEwen) and supplemented it with additional readings. Others starting a similar course might want to use Masculinity/Femininity in the same way. If they do, I think they will find several of the chapters particularly useful. One is the chapter by Goldfoot and Neff, which presents fascinating data on social factors and the development of behavioral sex differences in primates at the same time that it illustrates the logical and technical difficulties associated with studying sex differences. It also provides an excellent discussion of the relevance of animal studies to understanding human sex differences, an issue that always arises in my course. The chapter by Crews, which reviews the stunning variety of reproductive strategies used by such creatures as fish and reptiles, will also intrigue students. These animals have been studied less extensively than have mammals, but they have much to teach us regarding possible mechanisms by which masculinity and femininity are established. The most aweinspiring example for my students has been fish that change behavioral and physical sex in adulthood in response to changes in their social environment. These fish illustrate not only the diversity of possible reproductive strategies, but also the tyranny that environment, as well as biology, can exert on behavior. Finally, the chapter by Gorski should arouse students' interest in the biology of masculinity and femininity. It describes dramatic sex differences in the mammalian brain that can be strongly influenced by sex hormones. It also presents startling data on the behavioral consequences of transplanting hormonesensitive brain tissue from one animal to another, and on the role of sex hormones in the fundamental processes of brain development. This information is particularly useful for students, because it expands their understanding of the implications of research on masculinity and femininity far beyond discussion of which sex is better, to discussion of how our understanding of sex differences might help us understand our brains and our behavior in general.

In summary, this volume is an excellent review of current thought and research on the origins of masculine and feminine behavior. It provides an exciting and comprehensive introduction for students or others who are new to the field, as well as an informative and broadening update for those who are already familiar with it. I highly recommend it to both groups.

(Manuscript received August 22, 1988.) 